\title{
Peningkatan Kemampuan Guru dalam Melaksanakan Problem Based Learning melalui Supervisi Akademik di Sekolah
}

\author{
Maria Tatiana Erti \\ SMP Katolik Virgo Fidelis Maumere, Flores, NTT \\ Email: emilia.ssps@yahoo.com
}

\begin{abstract}
Abstrak
Proses Pembelajaran pada satuan pendidikan diselenggarakan secara interaktif, inspiratif, menyenangkan, menantang, memotivasi pesertadidik untuk berpartisipasi aktif, serta memberikan ruang yang cukup bagi prakarsa, kreativitas, dan kemandirian sesuai dengan bakat, minat, dan perkembangan fisik serta psikologis peserta didik (Permendiknas nomor 22 tahun 2016). Problem Based Learning merupakan salah satu model yang direkomendasikan dalam Kurikulum 2013untuk memperkuat pendekatan ilmiah (scientific). Kenyataannya, 70\% guru Matematika SMP Virgo Fidelisbelum memahami dan melaksanakan model Problem Based Learning secara baik dan benar. Melalui PTS ini, diharapkan dapat membantu guru Matematika dalam; 1) menyusun dan mengembangkan silabus, 2) menyusun dan mengembangkan Rencana Pelaksanaan Pembelajaran; 3) melaksanakan proses pembelajaran sesuai dengan RPP, dan model PBL.Penelitian tindakan sekolah (PTS) initerdiri dari 2 siklus, yang masingmasing siklus terdiri dari perencanaan (planning); tindakan (acting); observasi (observing); dan refleksi (reflecting), kemudian berlanjut dengan perencanaan ulang (replanning), tindakan, observasi, dan refleksi untuk siklus berikutnya (Arikunto (2011:16). Dari kondisi awal (pra siklus) ketercapaianpelaksananan PBL masih 44,44, setelah dilaksanakan tindakan siklus I meningkat menjadi 62,50 dengan kategori cukup. Melalui fokus pada indikator yangbelum terpenuhidijadikan bahan kajian untuk menentukan tindakan pada siklus II. Hasil evaluasi pada Siklus II, menunjukkan bahwa kemampuan guru-guru Matematika melaksanakan PBL meningkat menjadi 86,11 dengan kategor Sangat Baik. Hasil PTSmenunjukkan melalui supervisi akademik dan pendampingan dapat meningkatkan kemampuan guru dalam melaksanakan model Problem Based Learning dengan baik.
\end{abstract}

Kata Kunci: Kemampuan Guru Matematika, Problem Based Learning, Supervisi Akademik.

\section{Improvement of Teacher's Ability in Implementing Problem Based Learning through Academic Supervision in Schools}

\author{
Maria Tatiana Erti \\ SMP Katolik Virgo Fidelis Maumere, Flores, NTT \\ Email:emilia.ssps@yahoo.com
}

\begin{abstract}
Learning Processes in educational units are organized in an interactive, inspirational, fun, challenging, motivating participants to actively participate, and provide sufficient space for initiative, creativity and independence according to the talents, interests, and physical and psychological development of learners (Permendiknas Nomor 22 year 2016). Problem Based Learning is one of the recommended models in Kurikulum 2013 to strengthen the scientific (scientific) approach. In fact, $70 \%$ of students SMP Virgo Fidelis do not understand and implement the Problem Base Learning model properly and correctly. Through this PTS, is expected to assist math teacher in; 1) develop and develop syllabuses, 2) develop and develop the Lesson Plans; 3) implementing learning process in accordance with RPP, and PBL model. This school action research (PTS) consists of 2 cycles, each cycle consisting of planning; acting; observation (observing); and reflecting, then continuing with re-planning (replanning), action, observation, and reflection for the next cycle (Arikunto, 2011). From the initial condition (pre cycles) the achievement of PBL is still 44.44, after the first cycle action is increased to 62.50 with sufficient category. Through a focus on the unfulfilled indicators were used as the study material to determine actions in cycle II. The results of evaluation in Cycle II, showed that the ability of math teachers to implement PBL increased to 86.11 with Very Good categorization. The results of the PTS show through academic supervision and mentoring can improve the ability of teachers in implementing Problem Base Learning model well.
\end{abstract}

Keywords: Mathematic Teacher Ability, Problem Based Learning, Academic Supervision. 


\section{PENDAHULUAN}

Sesuai dengan Pasal 3 Undang-Undang Nomor 20 Tahun 2003 tentang Sistem Pendidikan Nasional, menegaskan bahwa pendidikan nasional berfungsi mengembangkan kemampuan dan membentuk watak serta peradaban bangsa yang bermartabat dalam rangka mencerdaskan kehidupan bangsa, bertujuan untuk mengembangkan potensi peserta didik agar menjadi manusia yang beriman dan bertakwa kepada Tuhan Yang Maha Esa, berakhlak mulia, sehat, berilmu, cakap, kreatif, mandiri, dan menjadi warga negara yang demokratis serta bertanggung jawab. Untuk menjamin pelayanan pendidikan yang bermutu sesuai dengan tuntutan perkembangan jaman maka peningkatan kompetensi ini merupakan suatu proses yang berkelanjutan.

Pitadjeng (2015), tugas profesi guru mencakup tugas mendidik, mengajar dan melatih. Menjadi tugas utama guru dalam melaksanakan proses pembelajaran sepenuhnya bertanggung jawab pada pengembangan ketiga ranah sikap, pengetahuan, dan keterampilan. Bloom Taxonomy mengkategorikan capaian pembelajaran menjadi tiga domain, yaitu dimensi pengetahuan yang terkait dengan penguasaan pengetahuan, dimensi sikap yang terkait dengan penguasaan sikap dan perilaku, serta dimensi ketrampilan yang terkait dengan penguasaan ketrampilan. Dimensi pengetahuan diklasifikasikan menjadi faktual, konseptual, prosedural, serta metakognitif yang penguasaannya dimulai sejak Tingkat Pendidikan Dasar hingga Tingkat Pendidikan Menengah (penjelasan Permendiknas Nomor 21 tahun 2016 tentang Standard Isi). Dengan demikian, tugas utama guru adalah bertanggung jawab membantu anak didik dalam hal belajar. Guru dikatakan telah berhasil dalam mengajar apabila tercapainya tujuan dan kualitas pembelajaran.

Setiap akan mengajar, guru perlu membuat Rencana Pelaksanaan Pembelajaran (RPP). Dalam persiapan itu sudah terkandung tentang, tujuan mengajar, pokok yang akan diajarkan, metode mengajar, bahan pelajaran, alat peraga dan teknik evaluasi yang digunakan. Setiap guru harus memahami benar tentang tujuan mengajar, secara khusus memilih dan menentukan metode mengajar sesuai dengan tujuan yang hendak dicapai, cara memilih, menentukan dan menggunakan alat peraga, cara membuat tes dan menggunakannya, dan pengetahuan tentang alat-alat evaluasi. Untuk memperkuat pendekatan ilmiah dan mendorong kemampuan peserta didik untuk menghasilkan karya kontekstual, baik individual maupun kelompok maka sangat disarankan dalam RPP menggunakan pendekatan pembelajaran yang menghasilkan karya berbasis pemecahan masalah (project based learning).

Dengan diberlakukannya kembali kurikulum 2013 yang menekan pada pendekatan scientifik, maka model pembelajaran berbasis (project based learning) menjadi salah satu model yang direkomendasikan. Namun kenyataannya pada SMPK Virgo Fidelis yang melaksanakan Kurikulum 2013 ditemukan lebih dari 70\% guru belum merealisasikan dan melaksanakan model-model pembelajaran yang menjadi tuntutan. Untuk menjaga agar kualitas pembelajaran sesuai dengan tuntutan kurikulum 2013, maka perlu adanya supervisi akademik.

Supervisi akademik bukan penilaian unjuk kerja pendidik melainkan membantu pendidik mengembangkan kemampuan profesionalismenya. Supervisi akademik merupakan fungsi kepala sekolah yang berkenaan dengan pelaksanaan tugas pembinaan, pemantauan, penilaian, serta pembimbingan dan pelatihan profesional guru baik pada aspek kompetensi maupun tugaspokoknya. Dengan supervisi akademik diharapkan dapat membantu guru dalam; 1) menyusun dan mengembangkan silabus, 2) 
menyusun dan mengembangkan Rencana Pelaksanaan Pembelajaran; 3) melaksanakan proses pembelajaran sesuai dengan RPP, terutama sesuai dengan tuntutan kurikulum 2013.

Untuk mewujudkan peningkatan kualitas profesi guru Matematika tidak akan terlepas adanya pembinaan dari kepala sekolah, karena bertugas melaksanakan pengawasan akademik yang ditunjuk melalui kegiatan pemantauan, penilaian, pembinaan, serta pelaporan dan tindak lanjut. Tanggung jawab kepala sekolah adalah meningkatkan kemampuan guru dalam melaksanakan dan meningkatnya mutu pembelajaran matematika agar dapat mempertinggi mutu hasil belajar siswa serta meningkatkan mutu lulusan. Untuk memecahkan masalah kekurangmampuan guru matematika dalam menerapkan pembelajaran berbasis masalah, maka kepala sekolah melakukan pendampingan dan pembinaan melalui penelitian tindakan sekolah. Penerapan model pendampingan berupa penelitian tindakan sekolah yang terdiri dari 2 siklus. Menurut Arikunto (2011:16), penelitian tindakan sekolah (PTS) yang digunakan ialah: perencanaan (planning); tindakan (acting); observasi (observing); dan refleksi (reflecting), kemudian berlanjut dengan perencanaan ulang (replanning), tindakan, observasi, dan refleksi untuk siklus berikutnya.

Dengan demikian, tujuan dilaksanakan penelitian tindakan sekolah oleh kepala sekolah yang dilaksanakan pada semester genap tahun pelajaran 2017/2018 ini adalah 1) untuk meningkatkan ketrampilan guru matematika menggunakan pembelajaran dengan model Problem Based Learning; 2) untuk mengungkap pengaruh pembelajaran dengan model Problem Based Learning terhadap motivasi dan hasil belajar siswa setelah guru menerapkan model pembelajaran tersebut.

\section{METODE}

Jenis penelitian ini merupakan penelitian tindakan sekolah (PTS) yang dilaksanakan oleh kepala sekolah kepada guru Mata Pelajaran Matematika, dan bertempat di SMP Virgo Fidelis, Kabupaten Sikka. Waktu penelitian direncanakan selama 4 bulan yaitu dari bulan Januari 2018 sampai dengan bulan Mei 2018. Prosedur pelaksanaan penelitian tindakan kelas ini meliputi 2 siklus, yang masing-masing siklus terdiri dari perencanaan (planning); tindakan (acting); observasi (observing); dan refleksi (reflecting), kemudian berlanjut dengan perencanaan ulang (replanning), tindakan, observasi, dan refleksi untuk siklus berikutnya (Arikunto, 2011:16).

Indikator keberhasilan proses tindakan adalah apabila guru Matematika pada sekolah binaan telah memahami dengan baik model Problem Based Learning dan mampu melaksanakannya dalam pembelajaran sehingga siswa dapat dengan cepat memahami materi ajar yang diberikan guru mereka. Indikator tersebut merupakan ratarata dari hasil pengamatan yang dilakukan oleh peneliti (observer I) dan kepala sekolah guru matematika yang bersangkutan (observer II).

\section{HASIL DAN PEMBAHASAN}

Analisis Data Penelitian Persiklus

Kondisi Awal

Berdasarkan hasil pemantauan melalui supervisi akademik pada guru matematika diSemester Ganjil Tahun Pelajaran 2017/2018 di SMP Virgo Fidelis ditemukan guru tidak melakukan pengembangan silabus dan pengembangan Rencana Pelaksanaan Pembelajaran (RPP) untuk kompetensi yang akan diajarkan. Metode dan model pembelajaran yang digunakan pun tidak terencana dengan baik, dan metode 
yang digunakannya metode ceramah. Akibat selanjutnya siswa menjadi pasif, kurang antusias, mengantuk, ngobrol sendiri dan ada pula yang mengerjakan mata pelajaran lain.

Data rata-rata hasil supervisi oleh kepala sekolah (peneliti) pengelolaan pembelajaran seperti disajikan pada tabel berikut.

Tabel 1. Pengelolan Pembelajaran Dengan Model Problem Based Learning Pada Pra Siklus

\begin{tabular}{|c|c|}
\hline Kemampuan Guru & $\frac{\text { Skor Hasil Observasi }}{\text { Observer I }}$ \\
\hline $\begin{array}{l}\text { 1) Memotivasi peserta didik untuk terlibat aktif dalam } \\
\text { pemecahan masalah yang dipilih. }\end{array}$ & 2 \\
\hline 2) Meningkatkan orientasi peserta didik kepada masalah & 1 \\
\hline $\begin{array}{l}\text { 3) Melaksanakan eksprimen untuk mendapatkan penjelasan dan } \\
\text { pemecahan masalah }\end{array}$ & 2 \\
\hline $\begin{array}{l}\text { 4) Merencanakan dan menyiapkan karya sesuai } \\
\text { laporan,model dan berbagi tugas }\end{array}$ & 1 \\
\hline 5) Mengevaluasi hasil belajar tentang materi yang telah dipelajari & 2 \\
\hline $\begin{array}{l}\text { 6) Membimbing siswa dalam penyelidikan individu dan } \\
\text { kelompok }\end{array}$ & 2 \\
\hline 7) Orientasi peserta didik kepada pemecahan masalah & 2 \\
\hline 8) Merancang RPP yang berbasis Problem Based Learning & 2 \\
\hline 9) Mendorong siswa mengembangkan bakat individu & 2 \\
\hline Rata-Rata & 1,48 \\
\hline Nilai & 44,44 \\
\hline
\end{tabular}

Dari data pada tabel 1 terlihat bahwa hampir semua indikator pelaksanaan mendapat nilai cukup dan kurang. Rata-rata ketercapaian pelaksanaan model PBL hanya $44,44 \%$ atau termasuk kategori kurang.

Dari hasil wawancara dengan guru, diperoleh data bahwa guru-guru sudah mengikuti kegiatan pendampingan kurikulum dengan Instruktur kabupaten(IK). Sedangkan hasil wawancara dengan guru Matematika, diketahui bahwa mereka belum memahami kurikulum2013 dengan baik, terutama penggunaan model-model pembelajaran. Kelemahan dan kekurangan pada tahap awal menjadi bahan kajian untuk menyusun perencanaan tindakan yang akan dilakukan pada siklus I.

\section{Siklus I}

Siklus I tindakan dilakukan tiga kali dengan skenario tindakan penelitian ini sebagai berikut: 1) membangun komitmen dengan bahasa positif, 2) diskusi bersama dalam kelompok dengan guru matematika untuk menyamakan pemahaman tentang Problem Based Learning, dan 3) Bersama-sama dengan Kepala sekolah (sebagai kolaborator) di sekolah masing-masing melaksanakan prosedur supervisi akademik. 
www.journal.univetbantara.ac.id/index.php/ijimm

Tabel 2. Pengelolan Pembelajaran Dengan Model Problem Based Learning Pada Siklus I

\begin{tabular}{|c|c|c|c|}
\hline \multirow{2}{*}{\multicolumn{2}{|c|}{ Kemampuan Guru }} & \multicolumn{2}{|c|}{ Skor Hasil Observasi } \\
\hline & & \multirow{2}{*}{$\frac{\text { Observer I }}{3}$} & \multirow{2}{*}{$\begin{array}{c}\text { Observer II } \\
3\end{array}$} \\
\hline 1) & $\begin{array}{l}\text { Memotivasi peserta didik untuk terlibat aktif dalam } \\
\text { pemecahan masalah yang dipilih. }\end{array}$ & & \\
\hline 2) & Meningkatkan orientasi peserta didik kepada masalah & 2 & 2 \\
\hline 3) & $\begin{array}{l}\text { Melaksanakan eksprimen untuk mendapatkan penjelasan } \\
\text { dan pemecahan masalah }\end{array}$ & 2 & 2 \\
\hline 4) & $\begin{array}{l}\text { Merencanakan dan menyiapkan karya sesuai } \\
\text { laporan,model dan berbagi tugas }\end{array}$ & 2 & 2 \\
\hline 5) & $\begin{array}{l}\text { Mengevaluasi hasil belajar tentang materi yang telah } \\
\text { dipelajari }\end{array}$ & 2 & 3 \\
\hline 6) & $\begin{array}{l}\text { Membimbing siswa dalam penyelidikan individu dan } \\
\text { kelompok }\end{array}$ & 3 & 3 \\
\hline 7) & Orientasi peserta didik kepada pemecahan masalah & 2 & 3 \\
\hline 8) & Merancang RPP yang berbasis Problem Based Learning & 3 & 3 \\
\hline 9) & Mendorong siswa mengembangkan bakat individu & 2 & 3 \\
\hline & a-Rata & 2.33 & 2.67 \\
\hline $\mathrm{Ni}$ & & & \\
\hline
\end{tabular}

Berdasarkan tabel di atas rata-rata nilai perolehan adalah 62,50 dengan kriteria cukup. Aspek-aspek yang mendapatkan kriteria kurang baik adalah memotivasi siswa, menyampaikan tujuan pembelajaran, meningkatkan orientasi peserta didik kepada masalah. Keempat aspek yang mendapat penilaian kurang baik di atas, merupakan suatu kelemahan yang terjadi pada siklus I dan menjadi bahan kajian untuk refleksi dan revisi yang akan dilakukan pada siklus II.

\section{Siklus II}

Pada siklus II bertujuan untuk lebih fokus dan menukik pada tindakan - tindakan pendampingan yang belum maksimal dilakukan pada siklus 1. Tindakan pada siklus I sama dengan tindakan II, ditambah dengan pembinaan melalui diskusi kelompok bersama-sama 3guru Matematika yang disupervisi, dan pendampingan secara individu di sekolah masing-masing.

Hasil observasi dilakukan berkolaborasi dengan kepala sekolah, diperoleh ratarata perolehan pengelolan pembelajaran dengan Model Problem Based Learning pada Siklus II sebagai berikut.

Tabel 3. Pengelolan Pembelajaran Dengan Model Problem Based Learning Pada Siklus II Kemampuan Guru

Skor Hasil Observasi

Observer I Observer II

\begin{tabular}{llll}
\hline 1) & $\begin{array}{l}\text { Memotivasi peserta didik untuk terlibat aktif dalam } \\
\text { pemecahan masalah yang dipilih. }\end{array}$ & 3 & 4 \\
\hline 2) & Meningkatkan orientasi peerta didik kepada masalah & 4 & 3 \\
\hline 3$)$ & $\begin{array}{l}\text { Melaksanakan eksprimen untuk mendapatkan } \\
\text { penjelasan dan pemecahan masalah }\end{array}$ & 3 & 4 \\
\hline 4$)$ & $\begin{array}{l}\text { Merencanakan dan menyiapkan karya sesuai :seperti } \\
\text { laporan,model dan berbagi tugas }\end{array}$ & 3 & 3 \\
\hline 5) & $\begin{array}{l}\text { Mengevaluasi hasil belajar tentang materi yang telah } \\
\text { dipelajari }\end{array}$ & 3 & 4 \\
\hline 6$)$ & Membimbing siswa dalam penyelidikan individu dan & 3 \\
\hline
\end{tabular}




\begin{tabular}{llcc}
\hline kelompok & 3 & \\
\hline 7) & Orientasi peserta didik kepada pemecahan masalah & 3 \\
\hline 8$)$ & $\begin{array}{l}\text { Merancang RPP yang berbasis Problem Based } \\
\text { Learning }\end{array}$ & 3 & 3 \\
\hline 9) & 3 & 4 \\
\hline Rata-Rata & 29 & 33 \\
\hline Nilai Rata-rata & \multicolumn{2}{c}{86,11} \\
\hline
\end{tabular}

Dari data pada tabel 3 hasil observasi menemukan terjadi peningkatan kualitas pelaksanaan supervisi terjadi di semua aspek yang diobservasi termasuk kategori Sangat Baik, yaitu mendapat rata-rata nilai 86,11. Dengan demikian, tujuan penelitian tercapai, angka ini di atas kriteria penelitian yang diajukan yaitu 70\%. Karena tujuan penelitian tindakan sudah tercapai, maka siklus III tidak dilaksanakan lagi.

Hasil penelitian menunjukkan terjadinya peningkatan kemampuan guru dari pra pelaksanaan penelitian sampai pada siklus II disajikan pada gambar berikut.

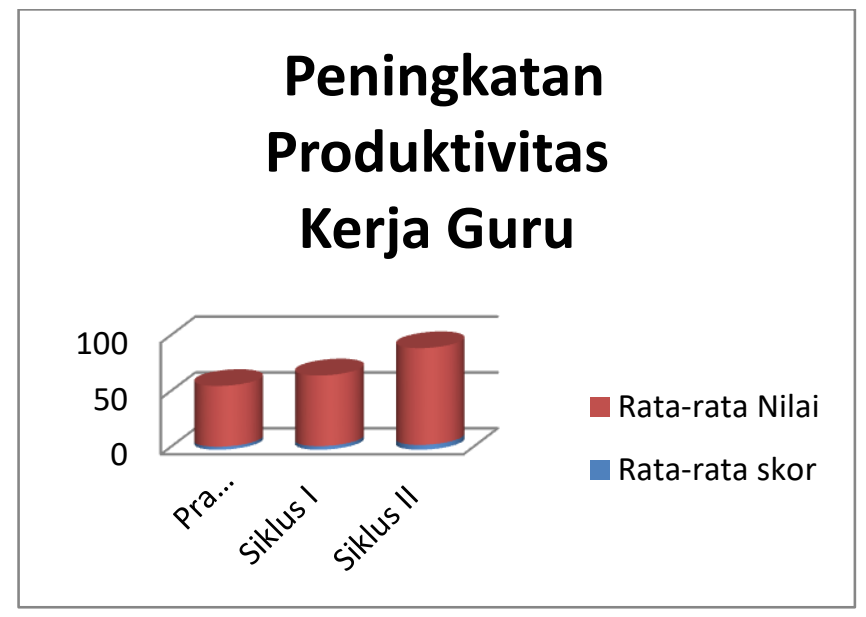

Gambar 1. Peningkatan Produktivitas Kerja Guru.

Gambar tersebut menunjukkan bahwa pada siklus I telah terjadi peningkatkan kemampuan guru Matematika dalam menggunakan pembelajaran Problem Based Learning, yaitu dari rata-rata nilai perolehan 44,44 (Sangat Kurang) menjadi 62,50 (Cukup) di akhir siklus I dan hal ini ditingkatkan lagi pada siklus II, dimana rata-rata nilai perolehan pada akhir siklus II telah mencapai 86,11 atau berada pada tingkatan sangat baik. Setyorini dkk (2011) model pembelajaran Problem Based Learning dapat meningkatkan kemampuan berpikir kritis siswa pada subpokok bahasan gerak lurus berubah beraturan. Hasil belajar siswa setelah penerapan PBL yakni jumlah siswa yang mencapai KKM sebanyak 29 siswa (100\%)(nafiah dan suyanto, 2016).

Gunantara dkk (2014) penerapan model pembelajaran Problem Based Learning (PBL) dapat meningkatkan kemampuan pemecahan masalah pada mata pelajaran Matematika. Prima dan kaniawati (2011) Adanya peningkatan penguasaan konsep yang lebih tinggi pada kelas eksperimen dengan perbedaan sangat signifikan dibandingkan dengan peningkatan penguasaan konsep pada kelas kontrol. 


\section{SIMPULAN DAN SARAN \\ SIMPULAN}

Simpulan dari hasil penelitian tindakan sekolah oleh kepala sekolah yang dilaksanakan pada semester genap tahun pelajaran 2017/2018 adalah: 1) Pembelajaran menggunakan model Problem Based Learning memiliki dampak positif dalam meningkatkan prestasi belajar peserta didik yang ditandai dengan peningkatan kemamapuan guru dari rata-rata setiap siklus; 2) Penerapan model Problem Based Learning mempunyai pengaruh positif, yaitu dapat meningkatkan motivasi belajar peserta didik; 3) Melalui supervisi akademik dan pembinaan guru-guru matematika dapat meningkatkan kemampuan merencanakan dan melaksanakan model Problem Based Learning dengan baik dan benar.

\section{SARAN}

1. Agar pelaksanaan pembelajaran dengan model Problem Based Learning memerlukan persiapan yang cukup matang, sehingga bisa diterapkan model tersebut agar diperoleh hasil optimal.

2. Guru hendaknya sering melatih peserta didik peserta didik dengan berbagai metode/model pembelajaran, agar berhasil atau mampu memecahkan masalahmasalah yang dihadapinya, sehingga berdampak pada meningkatkan prestasi belajarnya.

3. Kepala sekolah hendaknya melakukan supervisi akademik secara terencana dan berkesinambungan agar membantu guru dalam meningkatkan kemampuannya mengelola pembelajaran.

4. Perlu adanya penelitian yang lebih lanjut, karena hasil penelitian ini hanya dilakukan pada guru Matematika pada SMP Virgo Fidelis dan untuk penelitian yang serupa hendaknya dilakukan perbaikan-perbaikan agar diperoleh hasil yang lebih baik.

\section{DAFTAR REFERENSI}

Arikunto, S. (2011). Prosedur Penelitian Suatu Pendekatan Praktek. Jakarta: Rineksa

Djamarah dan Bahri S. (2002). Strategi Belajar Mengajar. Jakarta: Rineksa Cipta.

Erman. S. (2003). Strategi Pembelajaran Matematika Kontemporer. Bandung : JICA.

Fauzan. M, Gani. A, Syukri. M .2017. Penerapan Model Problem Based Learning Pada Pembelajaran Materi Sistem Tata Surya Untuk Meningkatkan Hasil Belajar Siswa. Jurnal Pendidikan Sains Indonesia. UNIVERSITAS SYIAH KUALA

Gulo. W, (2002). Strategi Belajar Mengajar. Jakarta: Grasindo

Gunantara. G ., Suarjana. I. M., dan Riastini. P. N. 2014. Penerapan Model Pembelajaran Problem Based Learning untuk Meningkatkan Kemampuan Pemecahan Masalah Matematika Siswa Kelas V. Jurnal Mimbar PGSD. UNDIKSA 
Hamalik, (2004). Proses Belajar Mengajar. Jakarta: Bumi Aksara

Nafiah. Y. N, dan Suyanto. W. (2016) Penerapan model problem-based learning untuk meningkatkan keterampilan berpikir kritis dan hasil belajar siswa. Jurnal pendidikan vokasi. Universitas negeri Yogyakarta.

Pitadjeng. (2005). Pembelajaran Matematika Yang Menyenangkan. Yogyakarta: Graha Ilmu Djamarah.

Prima. E. C.,dan Kaniawati. I. 2011. Penerapan model pembelajaran problem based learning dengan pendekatan inkuiri untuk meningkatkan keterampilan proses sains dan penguasaan konsep elastisitas pada siswa SMA. Jurnal pengajaran matematika dan ilmu pengetahuan alam. Universitas Pendidikan Indonesia.

Paloloang. M. F. B. 2014. Penerapan Model Problem Based Learning (PBL) untuk Meningkatkan Hasil Belajar Siswa pada Materi Panjang Garis Singgung Persekutuan Dua Lingkaran di kelas VIII SMP Negeri 19 Palu. Jurnal Elektronik Pendidikan Matematika Tadulako. UNTAD

Ruseffendi, E.T. (2006). Pengantar kepada Membantu Guru Mengembangkan Kompetensinya dalam Pengajaran Matematika untuk Meningkatkan CBSA. Bandung: Tarsito.

Suyadi. 2012. Penelitian Tindakan Kelas dan Penelitian Tindakan Sekolah. Yogyakarta: Andi.

U. Setyorini, S. E. Sukiswo, B. Subali. 2011. Penerapan Model Problem Based Learning Untuk Meningkatkan Kemampuan Berpikir Kritis Siswa SMP. Jurnal pendidikan fisika Indonesia. Universitas negeri semarang.

Utomo. T., wahyuni. D., dan haryadi S. 2014 Pengaruh Model Pembelajaran Berbasis Masalah (Problem BASED learning) Terhadap Pemahaman Konsep dan Kemampuan Berpikir Kreatif Siswa (siswa kelas VIII semester gasal SMPN 1 Sumbermalang Kabupaten Situbondo Tahun Ajaran 2012/2013). Jurnal Edukasi. Universitas Negeri Jember.

Usman dan Uzer. (2001). Menjadi Guru Profesional. Bandung: Remaja Rosdakarya. 